of profound biological importance with large practical bearings. It would be a disgrace to science, or rather to scientific men, were the present uncomfortable dead-lock of conflicting evidence to be permitted to remain for any length of time. Prof. Tyndall will, of course, publish descriptions of his experiments in the fullest possible detail; but the interested public have no just balance in which to weigh the accuracy and skill of Prof. Tyndall against that of Dr. Bastian. The high position of our great teachers undoubtedly carries with it certain obligations; and we scarcely think that we ask too much in the interest of science when we venture to suggest that steps should be taken towards the little friendly arrangement necessary for the settlement of the question.

\section{DOUGLAS A. SPALDING}

\section{OUR BOOK SHELF}

Solid Geometry. By Percival Frost, M.A. Vol. i. pp. 422. (London: Macmillan and Co., 1875.)

THIS excellent treatise is a revised and considerably enlarged second edition of the similar treatise brought out some few years since under the joint editorship of Messis. Frost and Wolstenholme. The engrossing duties consequent upon Mr. Wolstenholme's holding the post of Professor of Mathematics at Cooper's Hill, have prevented bis taking part in the bringing out of the present work. Great additions have been, and are being, made in this subject, as may be inferred from the fact that this first volume consists of 422 octavo pages, and even in this space many modes of treatment are omitted. "We cannot, however," writes Mr. Frost, "in a volume of moderate compass, pretend to include all the dual results to which our equations might give rise, but must confine ourselves to a development of the methods most generally usef́ul."

The author reserves for his second volume " those parts which are chiefly interesting as pure geometry, "bringing into the volume before us as much as he could, those parts of the subject which are more especially required by students who take up physical subjects. Prefixed to the texst is a full table of contents: indeed both in this work and that by Dr. Salmon on the same subject, the full list reminds us (though drawn up on different principles) of the diagnoses of the natural orders prefixed to text books on the British fora.

The text is written with extreme lucidity, and the diffculties to be met with in its per usal do not arise from the style, but from the inherent difficulty of the matters treated of. In two or three places we come across the phrases "easy to see," p. 154, "not hard to show," p. 157, and the like; of course here they are not intended to cover inability to expound the matter within reasonable compass, but still we think the proof might have been sketched out. When the student is going through the text step by step, he may even be able to work out the process by himself, but it is not so easy when the book is taken up at other times, when the previous steps in the reasoning are not fresh in the mind.

We note in Art. 192 that the elliptic sections are not pointed out; this and the definition of the radical plane (\$ i66) which reads somewhat curiously to our mind, are the only defects we have been able to detect-we had marked many passages for comment, but all is so carefully done, and the work brought down to the latest discoveries, that we shall content ourselves with saying that the book is well entitled to a place by the side of Dr. Salmon's treatise. Mr. Frost, it is well known, employs the term "conicoid" for the surface of the second degree, and in the present work he gives his reasons for persisting (as he expresses himself) in retaining the term. We must just cite here the concluding part of his remarks; the surface of the second degree, "well deserves a distinctive name instead of being recognised only by its number, a mode of designation which, I am informed, a convict feels very acutely. Man might be always called a biped, because besides himself there exist a quadruped, an octopus, and a centipede, but, on account of his superiority, it is more complimentary to call him by some special name."

The list of typographical errors is, we believe, very small, and all are easily corrigible by the reader. The appearance of the book leaves nothing to be desired.

Physiologische Methodik: ein Handbuch der Practischen Physiologie. Von Dr. Richard Gscheidlen, Professor an der Universität zu Breslau. Erste lieferung.

DR. GSCHEIDLEN has undertaken to supply physiological students with a book which undoubtedly they very much need. He proposes to give a detailed and full account of the instruments and methods of practical physiology, and to consider the experimental basis on which our knowledge of the functions of the animal body are founded.

The book is to be published in parts; the first part, which we have before us, treats at considerable length of the measurements of volume, temperature, time, \&c., needed in physiology and of the various instruments used in such measurements. It contains also the beginning of a chapter on physiological instruments and methods in general.

Altogether the present part gives good reason to hope that the work, when completed, will not only succeed in its main object of being useful to berrinners, but will also be a valuable book of reference in physiological ways and means. We shall, however, reserve detailed criticisms till the book is published as a whole. J. N. L.

\section{LETTERS TO THE EDITOR}

[The Editor does not hold himself responsible for opinions expressed by his correstondents. Neither can he undertake to return, or to correspond with the writers of, rejected manuscripts. No notice is taken of anonymous communnications.]

\section{Periodicity of the Fresh-water Lakes of Australia}

THE fresh.water lakes of Australia, though insignificant in size in comparison with the extent of the country, possess several features of considerable interest to the naturalist. Lake George, which is generally considered the largest sheet of fresh water on the Continent, is only some twenty-three or twenty-four miles in length and seven miles in breadth at the widest part, and even this lake had no existence twenty-four years ago. $A$ bit of swampy ground across which drays could pass, occupied, in I852, what is now the lowest part of the lake-bottom, and the rest was taken up by squatters and small farmers, who little dreamed, when they settled on the rich alluvial plain, that within a few years they would be hopelessly driven from their homes by the advancing waters. The present lake is situated, at an eleva. tion of about 2,000 feet above the sea, at the lower end of a shallow basin formed by a fork near the southern extremity of the Blue Mountains, and about 150 miles from Sydney. This basin is some forty to fifty miles in length, and from fifteen to twenty miles in breadth, the mountains rising somewhat rapidly to a height of several hundreds of feet on every side except the south. The depth of the water at the present time is only from 25 to 30 fect, which, considering the extent of land submerged, affords a strong argument in favour of the suppcsition that the lake existed in past times, and was at least as extensive as it is now. An examination of the banks of the creek which runs into the head of the lake confirmed this hypothesis, and led me to believe that it has at one time been much more extensive than it is at present, for the horizontal layers of alluvial deposit could be traced along either bank at an elevation of Io or I 2 feet above the present lake-surface. This, however, could not have been the case within the last one hundred years-probably not within many hundreds of years-for the present lake is fringed with broad expanses of partially submerged forest trees, that must have attained a growth of more than a century before the waters 